\title{
Noninvasive respiratory support for COVID-19 patients: when, for whom, and how?
}

\author{
Zachary P. Sullivan, Luca Zazzeron, Lorenzo Berra, Dean R. Hess, Edward A. Bittner and Marvin G. Chang*
}

\begin{abstract}
The significant mortality rate and prolonged ventilator days associated with invasive mechanical ventilation (IMV) in patients with severe COVID-19 have incited a debate surrounding the use of noninvasive respiratory support (NIRS) (i.e., HFNC, CPAP, NIV) as a potential treatment strategy. Central to this debate is the role of NIRS in preventing intubation in patients with mild respiratory disease and the potential beneficial effects on both patient outcome and resource utilization. However, there remains valid concern that use of NIRS may prolong time to intubation and lung protective ventilation in patients with more advanced disease, thereby worsening respiratory mechanics via selfinflicted lung injury. In addition, the risk of aerosolization with the use of NIRS has the potential to increase healthcare worker (HCW) exposure to the virus. We review the existing literature with a focus on rationale, patient selection and outcomes associated with the use of NIRS in COVID-19 and prior pandemics, as well as in patients with acute respiratory failure due to different etiologies (i.e., COPD, cardiogenic pulmonary edema, etc.) to understand the potential role of NIRS in COVID-19 patients. Based on this analysis we suggest an algorithm for NIRS in COVID-19 patients which includes indications and contraindications for use, monitoring recommendations, systems-based practices to reduce HCW exposure, and predictors of NIRS failure. We also discuss future research priorities for addressing unanswered questions regarding NIRS use in COVID-19 with the goal of improving patient outcomes.
\end{abstract}

Keywords: Noninvasive respiratory support (NIRS), High flow nasal cannula (HFNC), Continuous positive airway pressure (CPAP), Noninvasive ventilation (NIV), COVID-19, Invasive mechanical ventilation (IMV), SARS, MERS, H1N1, Hypoxemic respiratory failure, Acute respiratory failure (ARF), Acute respiratory distress syndrome (ARDS)

\section{Introduction}

The high mortality rate and prolonged ventilator days associated with invasive mechanical ventilation (IMV) reported in COVID-19 patients have renewed the discussion surrounding the utility of noninvasive respiratory support (NIRS), an umbrella term encompassing high flow nasal cannula (HFNC), continuous positive airway pressure (CPAP), and noninvasive ventilation (NIV). NIV has been shown to be efficacious in critically ill patients

*Correspondence: mgchang@partners.org Department of Anesthesia, Critical Care and Pain Medicine, Massachusetts General Hospital, MA, Boston, USA with conditions, such as chronic obstructive pulmonary disease (COPD), cardiogenic pulmonary edema, obstructive sleep apnea (OSA), and hypercapneic respiratory failure, whereas its utility is less clear in the management of patients with pneumonia, acute respiratory distress syndrome (ARDS), and particularly, COVID-19. Knowledge gained from the use of NIRS in prior viral pandemics such as SARS, MERS, and H1N1 may provide insight into appropriate use during the COVID-19 pandemic. Here, we outline the three most commonly utilized forms of NIRS, discuss the evolving literature pertaining to NIRS with and without proning, outline the aerosolization risks with different forms of NIRS, and original author(s) and the source, provide a link to the Creative Commons licence, and indicate if changes were made. The images or other third party material in this article are included in the article's Creative Commons licence, unless indicated otherwise in a credit line to the material. If material is not included in the article's Creative Commons licence and your intended use is not permitted by statutory regulation or exceeds the permitted use, you will need to obtain permission directly from the copyright holder. To view a copy of this licence, visit http://creativecommons.org/licenses/by/4.0/. The Creative Commons Public Domain Dedication waiver (http://creativeco mmons.org/publicdomain/zero/1.0/) applies to the data made available in this article, unless otherwise stated in a credit line to the data. 
review available evidence for the use of NIRS in patients with COVID-19 as well as in viral pneumonia from prior pandemics, ARDS, and community acquired pneumonia (CAP). Based on this analysis we suggest an algorithm for NIRS in COVID-19 patients which includes indications and contraindications for use, monitoring recommendations, practices to reduce $\mathrm{HCW}$ exposure, and predictors of NIRS failure. Finally, we discuss research priorities for addressing unanswered questions regarding the use of NIRS in COVID-19.

\section{Noninvasive respiratory support strategies}

Additional file 1: Text S1 outlines the most clinically used NIRS strategies (HFNC, CPAP, NIV), the risks and benefits of each, and the different delivery methods available, as well as a discussion of the ROX index which has been validated as a tool to assess the likelihood of HFNC failure in patients with acute hypoxemic respiratory failure.

\section{Modes of transmission and risk of aerosolization}

COVID-19 has various modes of transmission. While contact and fomite transmission do occur, the primary modes of transmission appear to be droplet and airborne. Airborne transmission is a direct result of inhalation of aerosolized viral particles. The primary differentiating factor between droplets and aerosols is size. According to the World Health Organization, respiratory droplets are greater than 5-10 $\mu \mathrm{m}$ in diameter, whereas aerosols are less than $5 \mu \mathrm{m}$ in diameter. Droplet transmission occurs within minutes of exposure to an infected individual and is typically the result of droplet formation from talking, singing, coughing, sneezing, or laughing. Due to the size and weight of droplet particles, they do not stay suspended in air for very long, and transmission typically occurs within six feet of the infected individual. In contrast, airborne transmission is a result of aerosolized particles remaining suspended in the air for a prolonged period of time, which makes this mode of transmission particularly concerning in large crowds, indoors, or in areas with poor ventilation. Of particular concern to healthcare workers is the role of aerosol generating procedures in the spread of COVID-19. Aerosol generating procedures such as laryngoscopy and bronchoscopy are thought to produce high concentrations of aerosolized particles which would increase the risk of airborne spread. While evidence remains lacking as to the precise proportion of spread that is due to airborne transmission from aerosolized particles, healthcare workers must remain vigilant when performing aerosol generating procedures to prevent inadvertent spread of COVID-19.

Much of our understanding of aerosolization associated with different ventilatory support strategies arose from research catalyzed by the previous pandemics of the twenty-first century. Yu et al. found six risk factors responsible for nosocomial spread of SARS which included minimum distance between beds $(\leq 1 \mathrm{~m})$, access to washing/changing facilities for staff, resuscitation administered on the ward, symptomatic staff continuing to work, and whether the patient required supplemental oxygen or NIV [1]. Limited evidence suggests that helmet NIV may reduce the risk of transmission to HCW [2]. A retrospective study which examined transmission risk of SARS to HCW in relation to patient's mode of ventilation found that among $\mathrm{HCW}$ who developed SARS, $38 \%$ had been exposed to patients receiving NIV, 35\% to patients undergoing intubation and mechanical ventilation, and $8 \%$ to patients receiving HFNC [3]. However, in a separate study of patients with acute respiratory failure secondary to SARS receiving NIV under strict conditions of patient isolation, adequate airflow, full personal protective equipment (PPE) of $\mathrm{HCW}$, and placement of a viralbacterial filter between the mask and the exhalation port, there were no $\mathrm{HCW}$ infections [4]. However, the primary complication associated with filter use, as discussed previously, is interference with ventilator function.

One of the feared complications of NIV in patients with transmissible respiratory infections is air leakage from an imperfect seal resulting in aerosolization of infective pathogens and a resultant superspreading event [5-7]. This concern is particularly relevant in COVID-19 in which the virus can remain actively infectious in aerosols for up to $3 \mathrm{~h}$ and is more enduring on plastic with evidence of viable virus detectable up to $72 \mathrm{~h}$ following surface exposure [8]. A study examining the dispersion of exhaled air via different ventilatory support strategies found CPAP via oronasal mask and NIV via helmet resulted in negligible air dispersion, whereas nasal cannula oxygen at $5 \mathrm{~L} / \mathrm{min}$ resulted in dispersion up to $1 \mathrm{~m}$ [9]. This study was completed in a negative pressure environment, thus results are not entirely generalizable. Another study of exhaled air dispersion found that the use of HFNC and CPAP with nasal pillows were both associated with exhaled air dispersion; however, air dispersion was negligible when CPAP was administered through an oronasal mask [10].

When utilizing HFNC, higher flows are likely to increase risk of aerosolization. The dispersion distance associated with HFNC use increased from $6.5 \pm 1.5 \mathrm{~cm}$ at a flow of $10 \mathrm{~L} / \mathrm{min}$ to $17.2 \pm 3.3 \mathrm{~cm}$ at a flow of $60 \mathrm{~L} / \mathrm{min}$ [10]. These are in comparison to a dispersion distance of $9.5 \pm 0.6 \mathrm{~cm}$ for face mask at $10 \mathrm{~L} / \mathrm{min}$ and a distance of $24.6 \pm 2.2 \mathrm{~cm}$ for a nonrebreather mask at $10 \mathrm{~L} / \mathrm{min}$ [11]. When using HFNC in pandemic medicine, it is advised to start at lower flows and as flow requirements increase it may be prudent to consider alternative respiratory strategies. It is also recommended that patients on HFNC 
with nasal prongs wear a surgical mask to limit exhaled air dispersion $[12,13]$. Loh et al. evaluated the impact of HFNC on dispersion distance when coughing and reported that cough droplets spread to a mean distance of $2.48 \mathrm{~m}$ at baseline, $2.91 \mathrm{~m}$ with HFNC at $60 \mathrm{~L} / \mathrm{min}$, and a maximum recorded distance of $4.5 \mathrm{~m}$ [14]. Leung et al. studied environmental bacterial contamination in pneumonia patients and found that HFNC, when compared to a standard oxygen mask, did not result in increased air or surface contamination by gram-negative bacteria [15].

In pandemic medicine, the use of a dual limb circuit for CPAP and NIV is far superior to a single limb circuit as the dual limb circuit is a closed system. If a single limb circuit is to be utilized, a viral filter should be placed over the leak port to further reduce the risk of aerosol dispersion. The lowest possible pressures should be used with CPAP and NIV, and the lowest possible flows with HFNC. While limiting the risk of aerosol dispersion is of clinical importance, in a review of HFNC use in COVID19, Lyons and Callaghan highlight the lack of current evidence regarding any clinically meaningful relationship between increased aerosolization and increased risk of spread to HCW [16]. On the contrary, recent evidence suggests that HFNC might not increase the risk of fugitive bioaerosols. Bem et al. quantified aerosol generation using laser light scattering and a particle counter and found that HFNC was not associated with increased aerosol generation compared to conventional oxygen therapy in both healthy individuals and in those with acute respiratory disease, including COVID-19 [17]. A recent editorial by $\mathrm{Li}$ and Scott reviewing current literature also suggests that the risk of transmission of COVID-19 with HFNC use is quite low [18]. Nevertheless, future research is necessary to more accurately quantify the degree of risk associated with HFNC use in COVID-19.

\section{Historical use and efficacy of noninvasive respiratory support}

In Additional file 2: Text S2, we review the effectiveness of NIRS in several disease states such as acute hypoxemic respiratory failure, ARDS, pneumonia, and past viral epidemics. We also compare the efficacy of different delivery methods of NIV.

\section{Noninvasive respiratory support in COVID-19}

It is well known that the clinical presentation of COVID-19 varies drastically, from asymptomatic to severe ARDS, multiorgan system failure and death. While it has been hypothesized that there may be different COVID-19 phenotypes that could explain the variance in clinical presentation, more evidence is needed to support those claims. Nevertheless, the heterogeneity witnessed in disease severity and presentation can make initial treatment challenging. It is known from studies in mechanically ventilated patients with ARDS that ventilation with high tidal volumes and elevated driving pressures may induce ventilator induced lung injury. In spontaneously breathing patients we may expect similar consequences if patients are breathing with large driving pressures and large tidal volumes without being appropriately monitored. Based on this concept, the traditional term ventilator-induced lung injury has been modified by some authors into ventilation-induced lung injury, to underline the fact that it is not the ventilator itself injuring the lung, but rather the unprotective ventilation. Along the same line, the concept of patient-self-inflicted lung injury (P-SILI) has been developed to describe the potential injurious ventilation in spontaneously breathing patients.

A recent study showed that the beneficial effect of lowering the tidal volume on mortality in mechanically ventilated patients with ARDS varies according to elastance, suggesting that lung protective ventilation strategies should target driving pressure rather than tidal volumes [19]. Whether this translates to spontaneously breathing patients is still unknown; however, this observation might be particularly relevant for patients with early COVID-19 ARDS, in which respiratory system compliance is often higher than in "classic" ARDS. A recent study showed that spontaneously breathing patients with COVID-19 ARDS have lower values of inspiratory effort as assessed by delta esophageal pressure, lower respiratory rate and lower minute volume ventilation as compared with patients with a similar degree of hypoxemia due to "classic" ARDS [20].

Ideally, to minimize the risk of injurious ventilation during spontaneous breathing, both tidal volume and driving pressure should be monitored. The use of esophageal manometry can help in determining the patient's work of breathing and estimate the driving pressure, although it requires placement of an esophageal balloon catheter in awake patients with respiratory distress and it is not yet considered a standard of care. While HFNC does not allow monitoring of tidal volume, NIV would provide some tidal volume measurement, although leaks at the NIV interface might affect measurements. Patients who are breathing with tidal volumes larger than $9 \mathrm{mg} /$ $\mathrm{kg}$ should be considered high risk for NIRS failure, and IMV should be strongly considered [21]. However, early intubation and mechanical ventilation for all patients at risk for P-SILI may not be the solution either, as there are several risks associated with IMV, including ventilator associated pneumonia, ventilator induced lung injury, prolonged sedation, prolonged immobility, and muscle wasting. Further research is needed to deepen our understanding of the role of P-SILI in COVID-19, and whether 
or not early intubation is an effective treatment strategy to reduce the incidence of P-SILI.

There remains limited data pertaining to the efficacy and safety of NIRS in the management of COVID-19. A prospective cohort study out of New York found that $22 \%$ of patients admitted with COVID-19 were critically ill and $79 \%$ of those critically ill patients required IMV [22]. Of those patients who required IMV, 62\% had first received some form of supplemental oxygen or NIRS (non-rebreather, HFNC or NIV) [22]. In comparison, a retrospective cohort study of COVID-19 patients in Wuhan, China found development of ARDS in $41.8 \%$ of admitted patients, ICU admission in $26.4 \%$, and death in $21.9 \%$ [23]. Of note, China took a different approach to oxygen therapy in COVID-19 patients, preferring noninvasive support over IMV. Of all patients hospitalized in the study, $48.8 \%$ received nasal cannula, $30.3 \%$ received some form of NIRS, and a mere $2.5 \%$ received IMV [23]. Of those patients who developed ARDS and survived, $42.5 \%$ had received nasal cannula and $57.5 \%$ had received NIRS [23]. Of those patients who developed ARDS and died, $86.4 \%$ had received NIRS and only $11.4 \%$ had received IMV [23]. A retrospective study of 318 COVID-19 patients in Chongqing, China found that $41 \%$ of patients admitted with ARF managed with HFNC as first line therapy experienced HFNC failure and required NIV as rescue therapy [24]. Of clinical importance, the HFNC failure rate was $0 \%$ in patients with $\mathrm{PaO}_{2} / \mathrm{FiO}_{2}>200 \mathrm{mmHg}$ and $63 \%$ in those with $\mathrm{PaO}_{2} /$ $\mathrm{FiO}_{2} \leq 200 \mathrm{mmHg}$ [24]. In addition, it was noted that the respiratory rate (RR) significantly decreased after $1-2 \mathrm{~h}$ of HFNC in the successful group but not in the unsuccessful group [24]. Of those who failed HFNC and required NIV as rescue therapy, $\mathrm{PaO}_{2} / \mathrm{FiO}_{2}$ significantly improved after 1-2 h of NIV; however, $29 \%$ of those patients ultimately required IMV [24]. This suggests that the rate of HFNC and NIV failure is not insignificant, which is especially appreciated in patients with severe ARDS.

Coppadoro et al. conducted an observational study to evaluate the efficacy of helmet CPAP on COVID-19 patients (study included both full code and DNI patients) who had failed standard oxygen therapy. Helmet CPAP was successful in treating $69 \%$ of full code patients and $28 \%$ of DNI patients [25]. Helmet CPAP was associated with significant improvement in oxygenation $\left(\mathrm{PaO}_{2} /\right.$ $\mathrm{FiO}_{2}$ increase of approximately 100) and respiratory distress (RR decrease from 28 to 24) [25]. Ing et al. suggest that helmet CPAP may be a safe, effective strategy in the management of hypoxemic respiratory failure secondary to COVID-19 so long as the patient is not showing signs of excessive inspiratory work or development of classic ARDS [26]. The HENIVOT trial by Grieco et al. evaluated the use of helmet NIV followed by HFNC versus
HFNC alone in the management of COVID-19 respiratory failure and found that there was no significant difference in median days free of respiratory support between groups; however, the helmet NIV group had significantly lower rates of IMV [27]. Duan et al. conducted a multicenter retrospective study of COVID-19 patients who received either HFNC or NIV as first line therapy and found no significant difference between groups in duration of NIRS, intubation, or mortality [28].

More recent literature pertaining to acute respiratory failure secondary to COVID-19 has the added benefit of providing clinicians with evidence-based outcomes that can help guide clinical decision-making. Liu et al. conducted a retrospective, multicenter observational study in an effort to develop a nomogram that would predict likelihood of NIRS failure in COVID-19 patients and found that predictors of NIRS failure included age, number of comorbidities, GCS score, ROX index, and vasopressor use on day one of NIRS [29]. Menga et al. conducted a prospective observational study evaluating the rate of NIRS failure in COVID-19 patients and reported a failure rate of $61 \%$, with failure defined as the need for IMV [30]. Interestingly, patients with hypoxemic respiratory failure secondary to COVID-19 were nearly twice as likely to fail a trial of NIRS compared to patients with non-COVID related hypoxemic respiratory failure [30]. Improvement in the $\mathrm{PaO}_{2} / \mathrm{FiO}_{2}$ ratio after one hour of NIRS was not predictive of NIRS success, whereas independent predictors of NIRS failure included SAPS II greater than 33 and LDH greater than 405 [30]. Hill and Devaraj hypothesize that the difference in NIRS failure rates between COVID and non-COVID-related hypoxemic respiratory failure may be due to the cytokine storm and subsequent multi-organ system failure associated with COVID-19 [31]. This may also explain why the initial improvement frequently seen in $\mathrm{PaO}_{2} / \mathrm{FiO}_{2}$ ratio in COVID-19 patients on a trial of NIRS is not consistently predictive of NIRS success [31]. The unique clinical course associated with COVID-19 hypoxemic respiratory failure is evidence that COVID-19 cannot be treated in the same manner as previous forms of hypoxemic respiratory failure, and that careful monitoring of patients on a trial of NIRS is required to prevent adverse outcomes associated with delayed intubation [31].

\section{Prone positioning}

One of the strategies utilized in the fight against COVID19 that has potential widespread implications for future management is awake prone positioning, both with and without concurrent use of NIRS, as reviewed in Additional file 3: Text S3. 


\section{Professional society guidelines for the use of NIRS in COVID-19}

The World Health Organization conducted a systematic review of ventilation strategies for coronavirus (the review included MERS, SARS and COVID-19) and concluded that NIV may reduce mortality and need for intubation, but that it also has the potential to increase spread to HCW [2]. Societal guidelines for the use of NIV as first line therapy for the management of COVID19 have been evolving as our understanding of the disease grows. HFNC is considered first line therapy by the Spanish Society of Pneumology and Thoracic Surgery, the European Society of Intensive Medicine, the Society of Critical Care Medicine, the Chinese Thoracic Society, and the Australian and New Zealand Intensive Care Society [32]. CPAP is considered first line therapy by the Italian Association of Hospital Pulmonologists (specifically helmet CPAP) and the National Health Service. HFNC or CPAP is recommended by the Portuguese Society of Pulmonology, HFNC or NIV by the World Health Organization, and helmet NIV by multiple German societies [32]. Recently updated SCCM guidelines provide a weak recommendation in favor of HFNC over NIV in patients with respiratory failure despite conventional oxygen [33]. SCCM also provides a weak recommendation in favor of NIV if HFNC is not available and there is no urgent indication for intubation [33].

\section{Implementation of noninvasive respiratory support in COVID-19}

Based on the literature review provided above, we posit that NIRS, when utilized in the appropriate setting, is an appropriate alternative to early IMV for patients presenting to the hospital with suspected or confirmed COVID19. However, stringent observation is necessary with NIRS to allow for early detection of clinical deterioration as NIRS failure is associated with increased risk of hospital mortality, ICU stay and hospital stay [34]. A recent publication by Raoof et al. outlines several indications and techniques for the use of NIRS in COVID-19 patients based on clinical presentation and symptom severity [35]. Raoof et al. advocate for supplemental oxygen in patients with no respiratory distress but with $\mathrm{SpO}_{2}<92-94 \%$ on room air (RA) or declining $\mathrm{SpO}_{2}$, with escalation to NIRS in patients with mild to moderate respiratory distress, increased work of breathing, $\mathrm{PaO}_{2} / \mathrm{FiO}_{2}>150$ but $<300$, or $\mathrm{SpO}_{2}<90-94 \%$ on non-rebreather [35]. They propose immediate IMV in patients with severe respiratory distress, $\mathrm{PaO}_{2} / \mathrm{FiO}_{2}<150$, or $\mathrm{SpO}_{2} / \mathrm{FiO}_{2}<196$ [35]. There is a large body of evidence in the literature pertaining to factors that predict NIV failure. These can be broadly divided into four categories. First, patient specific risk factors for NIRS failure include high APACHE II, high SAPS II, high SOFA, older age, multiorgan dysfunction, mask intolerance, poorly controlled respiratory secretions, neurologic impairment (measured via GCS), ARDS, pneumonia, worsening chest imaging, and failure to improve clinically after $1 \mathrm{~h}$ of NIRS [34, 36-42]. Second, laboratory values predictive of NIV failure include $\mathrm{pH}<7.25$ or $\mathrm{PaCO}_{2}>75$ (in hypercapnic ARF) after two hours of NIV, lack of improvement in blood gas, lower bicarbonate, lower $\mathrm{PaCO}_{2}$ (in hypoxemic ARF), higher lactate, and failure to maintain a $\mathrm{PaO}_{2}$ of $60 \mathrm{mmHg}$ on $\mathrm{FiO}_{2}$ of 0.6 [26, 34, 36-42]. Third, ventilatory predictors of NIV failure include $\mathrm{PaO}_{2} / \mathrm{FiO}_{2}<150-200$, a tidal volume of $>9.0-9.5 \mathrm{ml} / \mathrm{kg}$ of predicted body weight, and high peak pressure requirement [21, 26, 39-41, 43]. Finally, vital sign trends that are concerning for impending NIRS failure include increasing tachycardia, hemodynamic deterioration, and worsening dyspnea/tachypnea [26, 38-41].

a) Table 1 provides a list of indications for HFNC and NIV/CPAP in patients presenting to the hospital with COVID-19. NIV may be particularly beneficial for individuals with comorbid conditions such as COPD, obstructive sleep apnea, hypercapneic respiratory failure, cardiogenic pulmonary edema, CHF, and OSA. Table 2 provides our list of contraindications to NIRS. Due to the speed with which COVID19 patients can deteriorate, immediate intubation is warranted for any individual who presents with altered mental status, hemodynamic instability, multiorgan dysfunction, or severe hypoxaemia defined by an $\mathrm{SpO}_{2}$ of $<80 \%$, while on supplemental oxygen. Table 3 outlines our approach to the timely monitor-

Table 1 Indications for NIV and HFNC in the setting of Acute Respiratory Failure

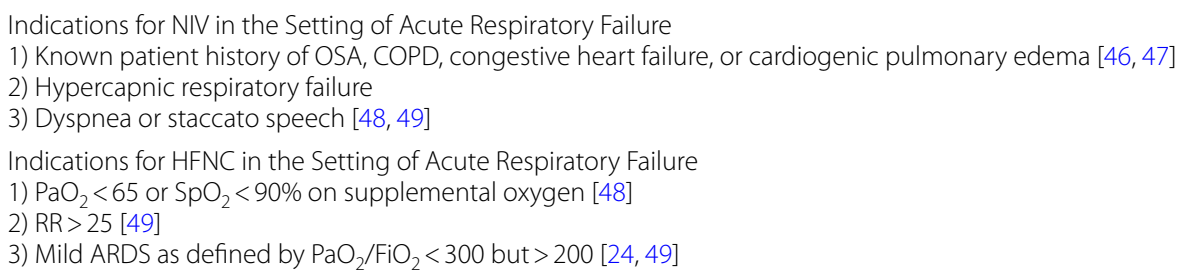


Table 2 Contraindication to Non-invasive Ventilation (NIV)

Contraindications to NIV

1) Cardiac and respiratory arrest

2) Encephalopathy or altered mentation [37]

3) Severe hypoxaemia on admission defined as $\mathrm{PaO}_{2} / \mathrm{FiO}_{2}<150$ [50]

4) Pneumothorax, pleural effusion, or pulmonary embolism [49]

5) Active upper gastrointestinal bleed, emesis, or aspiration risk [37]

6) Recent facial trauma or facial surgery [37]

7) Hemodynamic instability as defined by vasopressor use [37, 51]

8) Multiorgan dysfunction or failure [51]

9) SOFA score $>5$ is predictive of NIV failure $[51,52]$

10) Poorly controlled respiratory secretions $[37,39,53]$

11) CXR/CT showing evidence of bilateral, multilobar involvement [39, 51-53]

Table 3 Appropriate monitoring of Noninvasive Respiratory Support (NIRS)

Appropriate Monitoring of Noninvasive Respiratory Support

1) Hourly lab assessment (for $3 \mathrm{~h}$ )

a) $\mathrm{ABG}$ including $\mathrm{PaO}_{2}, \mathrm{PaCO}_{2}$, bicarbonate, lactate, and base excess

b) $\mathrm{PaO}_{2} / \mathrm{FiO}_{2}$ (target $\mathrm{PaO}_{2} / \mathrm{FiO}_{2}>300$ ) $[24,50]$

c) Subjective improvement or worsening of dyspnea [4]

2) Continuous monitoring (for $3 \mathrm{~h}$ ):

a) Heart rate and respiratory rate trends $[4,24]$

b) Pulse oximetry and $\mathrm{FiO}_{2}$ requirement

c) Tidal volume measurement if utilizing CPAP or NIV $[21,43,54]$ ing of COVID-19 patients undergoing a trial of NIRS. To prevent rapid and unpredicted patient decompensation, we recommend close monitoring for the first $3 \mathrm{~h}$. If a patient tolerates NIRS for $3 \mathrm{~h}$ without evidence of clinical deterioration, frequency of assessments can be liberalized based on the patient's condition and the physician's clinical judgement. Table 4 outlines multiple indicators of pending NIRS failure. As the number of indicators from Table 4 increases in a particular patient over time, the higher the likelihood of NIRS failure. Ultimately, however, these tables are meant to serve primarily as an adjunct and cognitive aid in the decision-making process. Table 5 outlines institutional level considerations to maximize the safety profile of NIRS and to limit spread to HCW. To minimize risk to health care workers, any COVID-19 patient receiving supplemental oxygen should be placed in an airborne isolation room if possible and staff caring for the patient should use full contact, droplet, and airborne isolation precautions $[44,45]$.

In an effort to develop a cognitive aid in the clinical decision-making process, Tables 1, 2, 3, 4 and 5 were used

Table 4 Primary and Secondary Indicators of Noninvasive Respiratory (NIRS) failure

Primary Indicators of Noninvasive Respiratory Support Failure

1) $\mathrm{PaO}_{2} / \mathrm{FiO}_{2}<150$ or inability to improve $\mathrm{PaO}_{2} / \mathrm{FiO}_{2}$ after 1 h of $\mathrm{NIV}[39,50,55]$

2) Worsening/unimproved dyspnea or tachypnea $>25$ after 1 h of NIV $[24,39,53,56]$

3) Failure to maintain $\mathrm{PaO}_{2}$ of 60 on $\mathrm{FiO}_{2}$ of $0.6[39,53]$

4) $\mathrm{SpO}_{2} / \mathrm{FiO}_{2}<196[35]$

5) Tidal volume of $>9 \mathrm{ml} / \mathrm{kg}$ predicted body weight $[21,43,54]$

6) ROX value less than 2.85 at $2 \mathrm{~h}$, less than 3.47 at $6 \mathrm{~h}$, or less than 3.85 at $12 \mathrm{~h}$ predict HFNC failure [57]

7) $\mathrm{pH}<7.25$ or $\mathrm{PaCO}_{2}>75$ after 2 h of NIV [42]

Secondary Indicators of Noninvasive Respiratory Support Failure

1) SAPS $\|>35$, APACHE $\|>17$, or rising SOFA score $[39,51,52,55]$

2) High peak pressure requirement $[39,53]$

3) Worsening bronchorrhea $[39,53]$

4) Intolerance of mask [39, 53]

Table 5 Safety considerations for Noninvasive Respiratory Support (NIRS) in COVID patients

Safety Considerations for Noninvasive Respiratory Support in COVID patients

1) Isolated negative pressure environment (room, hood, tent) [44]

a) Preferably with anteroom and private bathroom

2) Full contact, droplet, and airborne isolation precautions [44]

3) Full PPE that includes PAPR or N-95, gown, gloves, and face/eye shield [4]

4) Escalation of care to ICU for rapidly increasing $\mathrm{O}_{2}$ requirement or patients on NIV

5) NIV with helmet and tight air cushion or unvented oronasal mask [9]

a) Dual limb circuit over single limb circuits when utilizing CPAP or NIV

6) For single limb circuit, filter over leak port

7) Viral-bacterial filter between mask and exhalation port [4]

8) Staffing that allows for close monitoring to assess for deterioration

9) Sterile equipment nearby in preparation for emergent intubation in the event of rapid deterioration

10) Daily monitoring of HCW for symptoms[1] 


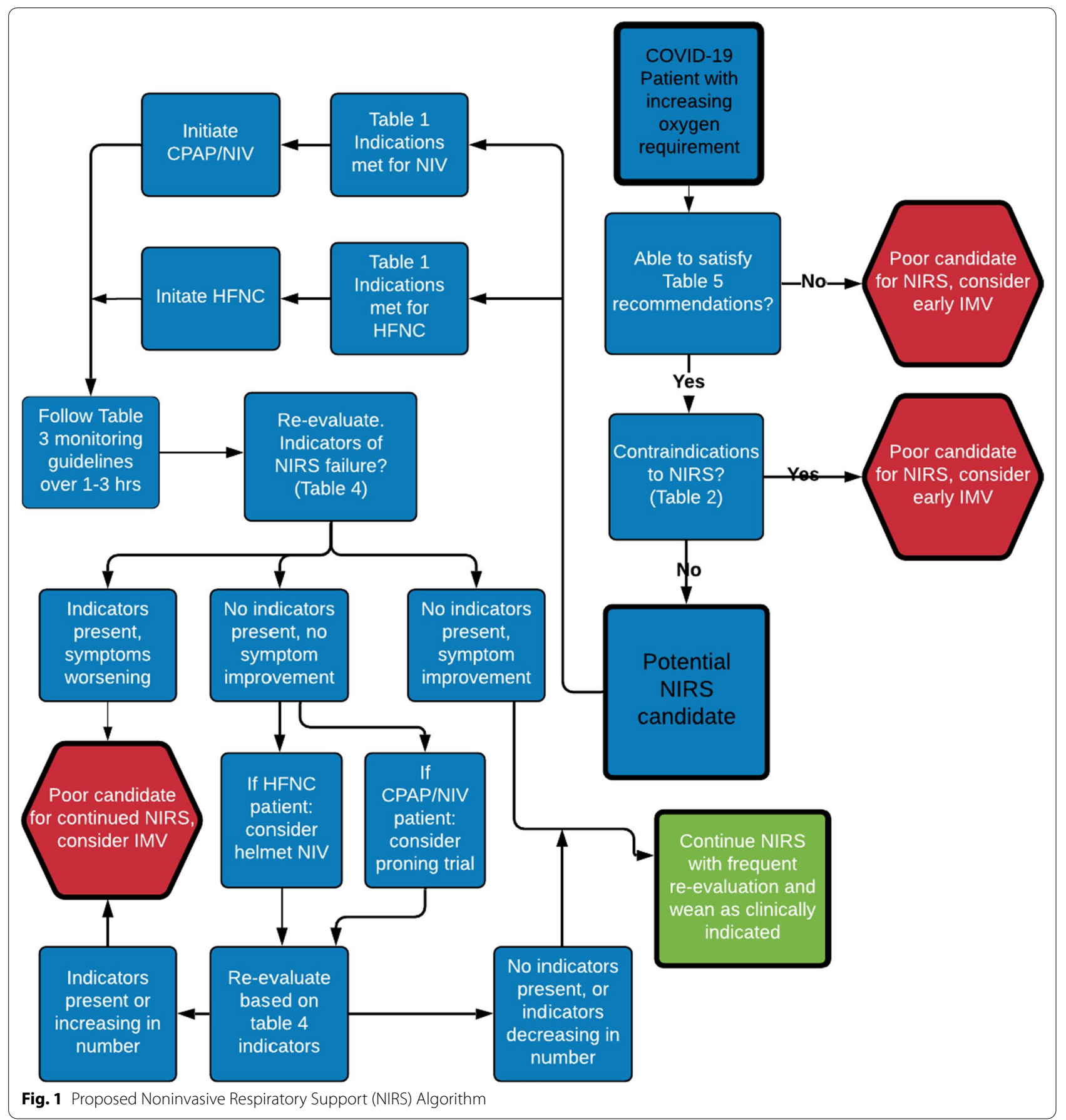

to create an algorithm (Fig. 1) for clinicians considering the use of NIRS. The primary aim of the algorithm is to assist clinicians in answering three clinical questions: 1 ) Is the patient a candidate for NIRS? 2) If the patient is a candidate, which NIRS modality should be utilized? and 3) What factors should be used to identify NIRS failure requiring IMV? In order for a patient to be considered a candidate for NIRS, the criteria in Table 4 should be met and there should be no contraindications present from Table 2. Per Society of Critical Care Medicine (SCCM) guidelines, initiation of HFNC over NIV is appropriate unless one of the specific indications for NIV in Table 1 is met, in which case NIV may be utilized over HFNC. Once NIRS is initiated, close monitoring should be conducted for approximately $3 \mathrm{~h}$, with a focus on HR, RR, hemodynamic stability, tidal volumes, and repeat blood 
gases to assess $\mathrm{PaO}_{2}, \mathrm{PaCO}_{2}$, and $\mathrm{PaO}_{2} / \mathrm{FiO}_{2}$ ratio. If at any point the patient begins to decompensate, develops a contraindication to NIRS (Table 2), or shows evidence of NIRS failure (Table 4), NIRS should be aborted in favor of immediate IMV. After the initial $3 \mathrm{~h}$ NIRS trial, if the patient has improved, it is appropriate to continue NIRS and wean as clinically indicated. If, however, the patient remains stable without evidence of significant improvement, the clinician may consider a trial of NIRS with prone positioning, with the understanding that there remains no recommendation in favor of or against prone positioning for COVID-19 from the SCCM due to a current lack of demonstrable evidence in its favor [33]. If the clinician determines the patient is a good candidate for a proning trial with NIRS, close monitoring for deterioration should be continued. Deterioration or lack of symptomatic improvement (as outlined by Tables 2, 3 and 4) after a proning trial should trigger escalation of care to IMV. See image one below for the associated algorithm. The algorithm is not meant to outline precisely which patients should and should not receive NIRS as there is a current lack of clinical evidence to that end; rather, the goal of the algorithm is to provide a working framework of evidence based cautions, contraindications, and management techniques for those physicians considering the use of NIRS in COVID-19 patients.

\section{Future considerations}

There appears to be a role for noninvasive respiratory support in the context of acute hypoxemic respiratory failure secondary to COVID-19, although more research is indicated to deepen our understanding of the precise benefits and risks associated with NIV for not only patients but also HCW [32]. A prospective RCT assessing outcomes such as intubation rate, ICU length of stay, and mortality in COVID-19 patients who are randomly assigned to one of two groups (immediate IMV vs. NIRS) with further subgroup analysis of outcomes for patients who fail NIRS and require IMV would go a long way in not only parsing out the efficacy of NIRS in COVID-19 patients, but would also provide insight into whether patients intubated following NIRS failure have better, worse, or equivocal outcomes compared to patients immediately intubated. As the COVID-19 pandemic continues to evolve, a stringent focus on which interventions objectively improve outcomes will be a valuable tool for clinicians, especially in situations of limited resources. Until that time, the use of NIRS in the management of COVID-19 can be considered safe and appropriate, particularly in the setting of potential ventilator shortages, when it is administered under the supervision of clinicians who understand not only the associated benefits and risks, but also when to appropriately transition to IMV.

\section{Conclusion}

Until future research provides clinically significant evidence pertaining to the efficacy of NIRS in the management of COVID-19, the judicious use of NIRS in select patients should be considered. A systems-based approach to the use of NIRS is strongly recommended and the safety practices outlined above would provide HCW with a significant degree of protection as we collectively work towards minimizing the likelihood of healthcare associated COVID-19 dissemination. When utilized with vigilance and under appropriate conditions, NIRS is an acceptable alternative to early IMV in the management of mild to moderate acute hypoxemic respiratory failure secondary to COVID-19.

\section{Take home message}

The mortality rate and prolonged ventilator days associated with invasive mechanical ventilation (IMV) of patients with severe COVID-19 have incited a debate surrounding the use of noninvasive respiratory support (NIRS) (i.e., HFNC, CPAP, NIV) as a potential treatment strategy. We review the existing literature with a focus on rationale, patient selection and outcomes associated with the use of NIRS in COVID-19 and prior pandemics, as well as in patients with acute respiratory failure due to different etiologies (i.e., COPD, cardiogenic pulmonary edema, etc.) to understand the potential role of NIRS in COVID-19 patients. Based on this analysis we suggest an algorithm for NIRS in COVID-19 patients which includes indications and contraindications for use, monitoring recommendations, systems-based practices to reduce healthcare worker ( $\mathrm{HCW}$ ) exposure, and predictors of NIRS failure.

\section{Supplementary Information}

The online version contains supplementary material available at https://doi. org/10.1186/s40560-021-00593-1.

Additional file 1: Text S1. Noninvasive respiratory support strategies. Additional file 2: Text S2. Historical use and efficacy of noninvasive respiratory support.

Additional file 3: Text S3. Prone positioning

\section{Acknowledgements \\ None.}

Authors' contributions

ZPS, LZ, LB, DRH, EAB, MGC wrote and reviewed the manuscript. All authors read and approved the final manuscript. 


\section{Funding \\ None.}

\section{Availability of data and materials}

Not applicable.

\section{Declarations}

\section{Ethics approval and consent to participate}

Not applicable.

\section{Consent for publication}

Not applicable.

\section{Competing interests}

ZPS, LZ, LB, EAB and MGC declare to have no competing interests. DRH discloses relationships with Ventec Life Systems, Lungpacer, UpToDate, McGrawHill, Jones and Bartlett, and Daedalus Enterprises.

Received: 30 September 2021 Accepted: 26 December 2021

Published online: 15 January 2022

\section{References}

1. Yu IT, Xie ZH, Tsoi KK, Chiu YL, Lok SW, Tang XP, Hui DS, Lee N, Li YM, Huang ZT, Liu T, Wong TW, Zhong NS, Sung JJ. Why did outbreaks of severe acute respiratory syndrome occur in some hospital wards but not in others? Clin Infect Dis. 2007;44:1017-25.

2. Schunemann HJ, Khabsa J, Solo K, Khamis AM, Brignardello-Petersen R, El-Harakeh A, Darzi A, Hajizadeh A, Bognanni A, Bak A, Izcovich A, Cuello-Garcia CA, Chen C, Borowiack E, Chamseddine F, Schunemann F, Morgano GP, Muti-Schunemann GEU, Chen G, Zhao H, Neumann I, Brozek J, Schmidt J, Hneiny L, Harrison L, Reinap M, Junek M, Santesso N, El-Khoury R, Thomas R, Nieuwlaat R, Stalteri R, Yaacoub S, Lotfi T, Baldeh T, Piggott T, Zhang Y, Saad Z, Rochwerg B, Perri D, Fan E, Stehling F, Akl IB, Loeb M, Garner P, Aston S, Alhazzani W, Szczeklik W, Chu DK, AkI EA. Ventilation techniques and risk for transmission of coronavirus disease, including COVID-19: a living systematic review of multiple streams of evidence. Ann Intern Med. 2020;173:204-16.

3. Raboud J, Shigayeva A, McGeer A, Bontovics E, Chapman M, Gravel D, Henry B, Lapinsky S, Loeb M, McDonald LC, Ofner M, Paton S, Reynolds D, Scales D, Shen S, Simor A, Stewart T, Vearncombe M, Zoutman D, Green K. Risk factors for SARS transmission from patients requiring intubation: a multicentre investigation in Toronto. Canada PLoS One. 2010;5:e10717.

4. Cheung TM, Yam LY, So LK, Lau AC, Poon E, Kong BM, Yung RW. Effectiveness of noninvasive positive pressure ventilation in the treatment of acute respiratory failure in severe acute respiratory syndrome. Chest. 2004; 126:845-50.

5. Arulkumaran N, Brealey D, Howell D, Singer M. Use of non-invasive ventilation for patients with COVID-19: a cause for concern? Lancet Respir Med. 2020;8:e45.

6. Singh A, Singh J. Noninvasive ventilation in acute respiratory failure due to H1N1 influenza: a word of caution. Lung India. 2011;28:151.

7. Tang JW, Li Y, Eames I, Chan PK, Ridgway GL. Factors involved in the aerosol transmission of infection and control of ventilation in healthcare premises. J Hosp Infect. 2006:64:100-14.

8. van Doremalen N, Bushmaker T, Morris DH, Holbrook MG, Gamble A, Williamson BN, Tamin A, Harcourt JL, Thornburg NJ, Gerber SI, Lloyd-Smith JO, de Wit E, Munster VJ. Aerosol and surface stability of SARS-CoV-2 as compared with SARS-CoV-1. N Engl J Med. 2020;382:1564-7.

9. Ferioli M, Cisternino C, Leo V, Pisani L, Palange P, Nava S. Protecting healthcare workers from SARS-CoV-2 infection: practical indications. Eur Respir Rev. 2020. https://doi.org/10.1183/16000617.0068-2020.

10. Hui DS, Chow BK, Lo T, Tsang OTY, Ko FW, Ng SS, Gin T, Chan MTV. Exhaled air dispersion during high-flow nasal cannula therapy versus CPAP via different masks. Eur Respir J. 2019. https://doi.org/10.1183/13993003. 02339-2018.

11. Ip M, Tang JW, Hui DS, Wong AL, Chan MT, Joynt GM, So AT, Hall SD, Chan PK, Sung JJ. Airflow and droplet spreading around oxygen masks: a simulation model for infection control research. Am J Infect Control. 2007;35:684-9.

12. Hui DS, Chow BK, Chu L, Ng SS, Lee N, Gin T, Chan MT. Exhaled air dispersion during coughing with and without wearing a surgical or N95 mask. PLOS ONE. 2012;7:e50845.

13 Li J, Fink JB, Ehrmann S. High-flow nasal cannula for COVID-19 patients: low risk of bio-aerosol dispersion. Eur Respir J. 2020. https://doi.org/10. 1183/13993003.00892-2020.

14. Loh NW, Tan Y, Taculod J, Gorospe B, Teope AS, Somani J, Tan AYH. The impact of high-flow nasal cannula (HFNC) on coughing distance: implications on its use during the novel coronavirus disease outbreak. Can J Anaesth. 2020:67:893-4.

15. Leung CCH, Joynt GM, Gomersall CD, Wong WT, Lee A, Ling L, Chan PKS, Lui PCW, Tsoi PCY, Ling CM, Hui M. Comparison of high-flow nasal cannula versus oxygen face mask for environmental bacterial contamination in critically ill pneumonia patients: a randomized controlled crossover trial. J Hosp Infect. 2019;101:84-7.

16. Lyons C, Callaghan M. The use of high-flow nasal oxygen in COVID-19. Anaesthesia. 2020;75:843-7.

17. Bem RA, van Mourik N, Klein-Blommert R, Spijkerman IJ, Kooij S, Bonn D, Vlaar AP. Risk of aerosol formation during high-flow nasal cannula treatment in critically III subjects. Respir Care. 2021;66:891-6.

18. Li J, Scott JB. Exploring and creating new evidence in a pandemic plays a crucial role in guiding clinical practice. Respir Care. 2021;66:1039-40.

19. Goligher EC, Costa ELV, Yarnell CJ, Brochard LJ, Stewart TE, Tomlinson G, Brower RG, Slutsky AS, Amato MPB. Effect of lowering vt on mortality in acute respiratory distress syndrome varies with respiratory system elastance. Am J Respir Crit Care Med. 2021;203:1378-85.

20. Tonelli R, Busani S, Tabbi L, Fantini R, Castaniere I, Biagioni E, Mussini C, Girardis M, Clini E, Marchioni A. Inspiratory effort and lung mechanics in spontaneously breathing patients with acute respiratory failure due to COVID-19: a matched control study. Am J Respir Crit Care Med. 2021:204:725-8.

21. Carteaux G, Millan-Guilarte T, De Prost N, Razazi K, Abid S, Thille AW, Schortgen F, Brochard L, Brun-Buisson C, Mekontso DA. Failure of noninvasive ventilation for de novo acute hypoxemic respiratory failure: role of tidal volume. Crit Care Med. 2016:44:282-90.

22. Cummings MJ, Baldwin MR, Abrams D, Jacobson SD, Meyer BJ, Balough EM, Aaron JG, Claassen J, Rabbani LE, Hastie J, Hochman BR, SalazarSchicchi J, Yip NH, Brodie D, O'Donnell MR. Epidemiology, clinical course, and outcomes of critically ill adults with COVID-19 in New York City: a prospective cohort study. Lancet. 2020;395:1763-70.

23. Wu C, Chen X, Cai Y, Xia J, Zhou X, Xu S, Huang H, Zhang L, Zhou X, Du C, Zhang Y, Song J, Wang S, Chao Y, Yang Z, XU J, Zhou X, Chen D, Xiong W, Xu L, Zhou F, Jiang J, Bai C, Zheng J, Song Y. Risk factors associated with acute respiratory distress syndrome and death in patients with coronavirus disease 2019 pneumonia in Wuhan China. JAMA Intern Med. 2020;180:934-43

24. Wang K, Zhao W, Li J, Shu W, Duan J. The experience of high-flow nasal cannula in hospitalized patients with 2019 novel coronavirus-infected pneumonia in two hospitals of Chongqing China. Ann Intensive Care. 2020;10:37.

25. Coppadoro A, Benini A, Fruscio R, Verga L, Mazzola P, Bellelli G, Carbone M, Mulinacci G, Soria A, Noe B, Beck E, Di Sciacca R, Ippolito D, Citerio G, Valsecchi MG, Biondi A, Pesci A, Bonfanti P, Gaudesi D, Bellani G, Foti G. Helmet CPAP to treat hypoxic pneumonia outside the ICU: an observational study during the COVID-19 outbreak. Crit Care. 2021;25:80.

26. Ing RJ, Bills C, Merritt G, Ragusa R, Bremner RM, Bellia F. Role of helmetdelivered noninvasive pressure support ventilation in COVID-19 patients. J Cardiothorac Vasc Anesth. 2020;34:2575-9.

27. Grieco DL, Menga LS, Cesarano M, Rosa T, Spadaro S, Bitondo MM, Montomoli J, Falo G, Tonetti T, Cutuli SL, Pintaudi G, Tanzarella ES, Piervincenzi E, Bongiovanni F, Dell'Anna AM, DelleCese L, Berardi C, Carelli S, Bocci MG, Montini L, Bello G, Natalini D, De Pascale G, Velardo M, Volta CA, Ranieri VM, Conti G, Maggiore SM, Antonelli M, Group C-IGS. Effect of helmet noninvasive ventilation vs high-flow nasal oxygen on days free of respiratory support in patients with COVID-19 and moderate to severe hypoxemic respiratory failure: the HENIVOT randomized clinical trial. JAMA. 2021;325:1731-43.

28. Duan J, Chen B, Liu X, Shu W, Zhao W, Li J, Li Y, Hong Y, Pan L, Wang K. Use of high-flow nasal cannula and noninvasive ventilation in patients 
with COVID-19: A multicenter observational study. Am J Emerg Med. 2021:46:276-81

29. Liu L, Xie J, Wu W, Chen H, Li S, He H, Yu Y, Hu M, Li J, Zheng R, Li X, Qiu H, Tong Z, Du B, Fan E, Yang Y, Slutsky AS. A simple nomogram for predicting failure of non-invasive respiratory strategies in adults with COVID-19: a retrospective multicentre study. Lancet Digit Health. 2021;3:e166-74.

30. Menga LS, Cese LD, Bongiovanni F, Lombardi G, Michi T, Luciani F, Cicetti M, Timpano J, Ferrante MC, Cesarano M, Anzellotti GM, Rosa T, Natalini D, Tanzarella ES, Cutuli SL, Pintaudi G, De Pascale G, Dell'Anna AM, Bello G, Pennisi MA, Maggiore SM, Maviglia R, Grieco DL, Antonelli M. High failure rate of noninvasive oxygenation strategies in critically III subjects with acute hypoxemic respiratory failure due to COVID-19. Respir Care. 2021;66:705-14.

31. Hill NS, Devaraj A. Noninvasive ventilation strategies in the age of COVID19: an evolving story. Respir Care. 2021;66:878-80.

32. Winck JC, Ambrosino N. COVID-19 pandemic and non invasive respiratory management: every Goliath needs a David. An evidence based evaluation of problems. Pulmonology. 2020;26:213-20.

33. Alhazzani W, Evans L, Alshamsi F, Moller MH, Ostermann M, Prescott HC, Arabi YM, Loeb M, Ng Gong M, Fan E, Oczkowski S, Levy MM, Derde L, Dzierba A, Du B, Machado F, Wunsch H, Crowther M, Cecconi M, Koh Y, Burry L, Chertow DS, SzczeklikW, Belley-Cote E, Greco M, Bala M, Zarychanski R, Kesecioglu J, McGeer A, Mermel L, Mammen MJ, NainanMyatra S, Arrington A, Kleinpell R, Citerio G, Lewis K, Bridges E, Memish ZA, Hammond N, Hayden FG, Alshahrani M, Al Duhailib Z, Martin GS, Kaplan LJ, Coopersmith CM, Antonelli M, Rhodes A. Surviving sepsis campaign guidelines on the management of adults with coronavirus disease 2019 (COVID-19) in the ICU: first update. Crit Care Med. 2021;49:e219-34.

34. Correa TD, Sanches PR, de Morais LC, Scarin FC, Silva E, Barbas CS. Performance of noninvasive ventilation in acute respiratory failure in critically ill patients: a prospective, observational, cohort study. BMC Pulm Med. 2015;15:144.

35. Raoof S, Nava S, Carpati C, Hill NS. High-flow, noninvasive ventilation and awake (nonintubation) proning in patients with coronavirus disease 2019 with respiratory failure. Chest. 2020;158:1992-2002.

36. Antonelli M, Conti G, Moro ML, Esquinas A, Gonzalez-Diaz G, Confalonieri M, Pelaia P, Principi T, Gregoretti C, Beltrame F, Pennisi MA, Arcangeli A, Proietti R, Passariello M, Meduri GU. Predictors of failure of noninvasive positive pressure ventilation in patients with acute hypoxemic respiratory failure: a multi-center study. Intensive Care Med. 2001;27:1718-28.

37. Chawla R, Dixit SB, Zirpe KG, Chaudhry D, Khilnani GC, Mehta Y, Khatib Kl, Jagiasi BG, Chanchalani G, Mishra RC, Samavedam S, Govil D, Gupta S, Prayag S, Ramasubban S, Dobariya J, Marwah V, Sehgal I, Jog SA, Kulkarni AP. ISCCM guidelines for the use of non-invasive ventilation in acute respiratory failure in adult ICUs. Indian J Crit Care Med. 2020;24:S61-81.

38. Duan J, Han X, Bai L, Zhou L, Huang S. Assessment of heart rate, acidosis, consciousness, oxygenation, and respiratory rate to predict noninvasive ventilation failure in hypoxemic patients. Intensive Care Med. 2017:43:192-9.

39. Egea N, Cazaux A, Langer M, Cambursano H. Noninvasive positivepressure ventilation in patients with acute hypoxemic respiratory failure and HIV/AIDS. In: Esquinas AM, editor. Noninvasive ventilation in high-risk infections and mass casualty events. Vienna: Springer; 2014. p. 85-97.

40. Hilbert G, Gruson D, Vargas F, Valentino R, Gbikpi-Benissan G, Dupon M, Reiffers J, Cardinaud JP. Noninvasive ventilation in immunosuppressed patients with pulmonary infiltrates, fever, and acute respiratory failure. N Engl J Med. 2001;344:481-7.

41. Organized jointly by the American Thoracic Society tERStESolCM, the Societe de Reanimation de Langue F and approved by Ats Board of Directors D. International Consensus Conferences in Intensive Care Medicine: noninvasive positive pressure ventilation in acute Respiratory failure. Am J Respir Crit Care Med. 2001;163:283-91.

42. Smith DB, Tay GTP, Hay K, Antony J, Bell B, Kinnear FB, Curtin DL, Douglas J. Mortality in acute non-invasive ventilation. Intern Med J. 2017:47:1437-40.

43. Frat JP, Ragot S, Coudroy R, Constantin JM, Girault C, Prat G, Boulain T, Demoule A, Ricard JD, Razazi K, Lascarrou JB, Devaquet J, Mira JP, Argaud L, Chakarian JC, Fartoukh M, Nseir S, Mercat A, Brochard L, Robert R, Thille AW, Network R. Predictors of intubation in patients with acute hypoxemic respiratory failure treated with a noninvasive oxygenation strategy. Crit Care Med. 2018:46:208-15.
44. Greenland JR, Michelow MD, Wang L, London MJ. COVID-19 Infection: Implications For Perioperative And Critical Care Physicians. Anesthesiology. 2020;132:1346-61.

45. Wax RS, Christian MD. Practical recommendations for critical care and anesthesiology teams caring for novel coronavirus (2019-nCoV) patients. Can J Anaesth. 2020;67:568-76.

46 Confalonieri M, Potena A, Carbone G, Porta RD, Tolley EA, Umberto MG. Acute respiratory failure in patients with severe community-acquired pneumonia. A prospective randomized evaluation of noninvasive ventilation. Am J Respir Crit Care Med. 1999;160:1585-91.

47. David-Joao PG, Guedes MH, Rea-Neto A, Chaiben VBO, Baena CP. Noninvasive ventilation in acute hypoxemic respiratory failure: a systematic review and meta-analysis. J Crit Care. 2019;49:84-91.

48. Piva S, Filippini M, Turla F, Cattaneo S, Margola A, De Fulviis S, Nardiello I, Beretta A, Ferrari L, Trotta R, Erbici G, Foca E, Castelli F, Rasulo F, Lanspa MJ, Latronico N. Clinical presentation and initial management critically ill patients with severe acute respiratory syndrome coronavirus 2 (SARSCoV-2) infection in Brescia Italy. J Crit Care. 2020;58:29-33.

49 Radovanovic D, Rizzi M, Pini S, Saad M, Chiumello DA, Santus P. Helmet CPAP to treat acute hypoxemic respiratory failure in patients with COVID19: a management strategy proposal. J Clin Med. 2020. https://doi.org/10. 3390/jcm9041191.

50. Bellani G, Laffey JG, Pham T, Madotto F, Fan E, Brochard L, Esteban A, Gattinoni L, Bumbasirevic V, Piquilloud L, van Haren F, Larsson A, McAuley DF, Bauer PR, Arabi YM, Ranieri M, Antonelli M, Rubenfeld GD, Thompson BT, Wrigge H, Slutsky AS, Pesenti A, Investigators LS and Group ET. Noninvasive ventilation of patients with acute respiratory distress syndrome. Insights from the LUNG SAFE Study. Am J Respir Crit Care Med. 2017;195:67-77.

51. Masclans JR, Perez M, Almirall J, Lorente L, Marques A, Socias L, Vidaur L, Rello J, Investigators HNGS. Early non-invasive ventilation treatment for severe influenza pneumonia. Clin Microbiol Infect. 2013;19:249-56.

52. Rodriguez A, Ferri C, Martin-Loeches I, Diaz E, Masclans JR, Gordo F, Sole-Violan J, Bodi M, Aviles-Jurado FX, Trefler S, Magret M, Moreno G, Reyes LF, Marin-Corral J, Yebenes JC, Esteban A, Anzueto A, Aliberti S, Restrepo MI, GrupoEspanol de Trabajo Gripe A Grave /Sociedad Espanola de MedicinalntensivaCyUCWG and investigators HNSWG. Risk Factors for Noninvasive Ventilation Failure in Critically III Subjects With Confirmed Influenza Infection. Respir Care. 2017;62:1307-15.

53. Nie QH, Luo XD, Zhang JZ, Su Q. Current status of severe acute respiratory syndrome in China. World J Gastroenterol. 2003;9:1635-45.

54. Keenan SP, SinuffT, Burns KE, Muscedere J, Kutsogiannis J, Mehta S, Cook DJ, Ayas N, Adhikari NK, Hand L, Scales DC, Pagnotta R, Lazosky L, Rocker G, Dial S, Laupland K, Sanders K, Dodek P, Canadian Critical Care Trials Group/Canadian Critical Care Society Noninvasive Ventilation Guidelines G. Clinical practice guidelines for the use of noninvasive positive-pressure ventilation and noninvasive continuous positive airway pressure in the acute care setting. CMAJ. 2011. https://doi.org/10.1503/cmaj.100071.

55. Antonelli M, Conti G, Esquinas A, Montini L, Maggiore SM, Bello G, Rocco M, Maviglia R, Pennisi MA, Gonzalez-Diaz G, Meduri GU. A multiple-center survey on the use in clinical practice of noninvasive ventilation as a firstline intervention for acute respiratory distress syndrome. Crit Care Med. 2007:35:18-25.

56. Yam LY, Chen RC, Zhong NS. SARS: ventilatory and intensive care. Respirology. 2003:8(Suppl):S31-5.

57. Roca O, Caralt B, Messika J, Samper M, Sztrymf B, Hernandez G, Garcia-deAcilu M, Frat JP, Masclans JR, Ricard JD. An index combining respiratory rate and oxygenation to predict outcome of nasal high-flow therapy. Am J Respir Crit Care Med. 2019;199:1368-76.

\section{Publisher's Note}

Springer Nature remains neutral with regard to jurisdictional claims in published maps and institutional affiliations. 